\title{
Hypoparathyroidism after total thyroidectomy in patients with previous gastric bypass
}

\author{
Raoul A. Droeser ${ }^{1} \cdot$ Johan Ottosson $^{2} \cdot$ Andreas Muth $^{3} \cdot$ Hella Hultin $^{4}$. \\ Karin Lindwall-Åhlander ${ }^{5}$ • Anders Bergenfelz ${ }^{6}$ - Martin Almquist ${ }^{6,7}$
}

Received: 31 May 2016 / Accepted: 16 September 2016/Published online: 26 October 2016

(C) The Author(s) 2016. This article is published with open access at Springerlink.com

\begin{abstract}
Purpose Case reports suggest that patients with previous gastric bypass have an increased risk of severe hypocalcemia after total thyroidectomy, but there are no population-based studies. The prevalence of gastric bypass before thyroidectomy and the risk of hypocalcemia after thyroidectomy in patients with previous gastric bypass were investigated.

Methods By cross-linking The Scandinavian Quality Registry for Thyroid, Parathyroid and Adrenal Surgery with the Scandinavian Obesity Surgery Registry patients operated with total thyroidectomy without concurrent or previous surgery for hyperparathyroidism were identified and grouped according to previous gastric bypass. The risk of treatment with intravenous calcium during hospital stay, and with oral calcium and vitamin D at 6 weeks and 6 months postoperatively
\end{abstract}

Electronic supplementary material The online version of this article (doi:10.1007/s00423-016-1517-x) contains supplementary material, which is available to authorized users.

Martin Almquist

martin.almquist@med.lu.se

1 Sten Tibblin Fellow, Dept. of Surgery, Skane University Hospital, Lund, Sweden

2 Dept. of Surgery, Faculty of Medicine and Health, Örebro University, Örebro, Sweden

3 Dept. of Surgery, Institute of Clinical Sciences, Sahlgrenska Academy, University of Gothenburg, Gothenburg, Sweden

4 Dept. of Surgery, Akademiska Hospital, Uppsala, Sweden

5 Dept. of Surgery, Gävle County Hospital, Gävle, Sweden

6 Dept. of Surgery, Skane University Hospital, S-221 85 Lund, Sweden

7 Lund University, S-221 85 Lund, Sweden was calculated by using multiple logistic regression in the overall cohort and in a 1:1 nested case-control analysis.

Results We identified 6115 patients treated with total thyroidectomy. Out of these, $25(0.4 \%)$ had undergone previous gastric bypass surgery. In logistic regression, previous gastric bypass was not associated with treatment with i.v. calcium (OR 2.05, $95 \%$ CI 0.48-8.74), or calcium and/or vitamin D at 6 weeks $(1.14(0.39-3.35), 1.31(0.39-4.42))$ or 6 months after total thyroidectomy (1.71 (0.40-7.32), $2.28(0.53-9.75))$. In the nested case-control analysis, rates of treatment for hypocalcemia were similar in patients with and without previous gastric bypass.

Conclusion Previous gastric bypass surgery was infrequent in patients undergoing total thyroidectomy and was not associated with an increased risk of postoperative hypocalcemia.

Keywords Total thyroidectomy · Gastric bypass · Postoperative hypoparathyroidism $\cdot$ Cohort study

\section{Introduction}

Several case reports indicate that previous bariatric surgery for morbid obesity constitutes a risk factor for severe hypocalcemia after total thyroidectomy (TT) [1-3]. Gastric bypass surgery (GBP) is the most commonly performed procedure for morbid obesity, and due to the worldwide obesity epidemic, the prevalence of previous GBP is increasing [4]. Hypocalcemia is the most common complication of TT [5] [6] and is caused by intraoperative injury to the parathyroid glands or their blood supply [7]. Low level vitamin D can also aggravate postoperative hypocalcemia [8]. Patients with GBP are at risk of developing nutritional deficiencies [9] [10]. In GBP, the absorption of calcium and vitamin D is diminished, possibly due to the exclusion of the duodenum and proximal 
jejunum, where active vitamin D-associated calcium uptake occurs [11]. Accordingly, patients with GBP have lower levels of vitamin D (25OHD) than the general population [12]. However, it has been shown that 25OHD levels in GBP patients are equally low before and after GBP [13]. Low levels of 25OHD also persist at long-term follow up after GBP, together with the increased levels of parathyroid hormone (PTH), decreased bone mineral density, and increased risk of fractures [12-14]. This has led to the recommendation of calcium and vitamin D supplementation after GBP [15]. Thus, patients with previous GBP could be at increased risk of hypocalcemia after TT.

Hypocalcemia after TT can cause unpleasant symptoms, leading to increased costs for sick leave, follow-up visits, and readmission [16] [17]. Therefore, identifying risk factors for hypocalcemia is important. Patients with increased risk for this complication could benefit from a longer hospital stay, increased surveillance, and/or preoperative treatment with calcium and/or vitamin D.

Apart from case reports [1-3], there has been no population-based study investigating hypocalcemia after TT in relation to GBP. Thus, we aimed to investigate the frequency and severity of postoperative hypocalcemia in patients with previous GBP undergoing TT, and whether GBP increases the risk for hypocalcemia after TT, using data from nationwide, clinical registers.

\section{Material and methods}

\section{Data sources}

\section{SQRTPA}

The Scandinavian Quality Registry for Thyroid, Parathyroid and Adrenal Surgery (SQRTPA, www.thyroidparathyroidsurgery.com) started in 2004 and is recognized by the Swedish National Board for Health and Social Welfare as the national quality registry for endocrine surgical procedures in Sweden. Currently, 35 Swedish units report to the registry, covering $88 \%$ of all procedures during the study period. Coverage is assessed by calculating the proportion of patients registered in the SQRTPA in relation to those registered in the Inpatient Register of the Swedish National Board of Health and Welfare. The quality of data for the registered patients is checked by external audit, comparing registered data to hospital medical records. The audit has demonstrated good data quality, with an error rate of $<5 \%[18,19]$.

\section{SOReg}

The Swedish Obesity Registry, SOReg, started in May 2007. All Swedish bariatric units are affiliated with this register. The national coverage is $97 \%$ and regular data quality evaluations have shown that $>98 \%$ of data are correct [20].

\section{Study cohort}

Patients operated with TT between 1 January 2004 and 31 December 2015 were identified in the SQRTPA. Patients with concurrent or previous surgery for hyperparathyroidism were excluded, as were patients with missing information on postoperative hypocalcemia. By cross-linking with the SOReg, information on GBP was obtained.

\section{Ethical considerations}

This study was approved by the research ethics committee at Lund University, DNR 2015/543 and 2016/83.

\section{Data}

Endpoint data concerning postoperative oral and intravenous (i.v.) calcium and vitamin $\mathrm{D}$ treatment during hospital stay, at discharge, and at 6 weeks and 6 months postoperatively were extracted from the SQRTPA. Further, data on age, sex, indication for thyroidectomy, and lymph node dissection were retrieved.

\section{Statistical analysis}

The risk of hypocalcemia after TT in patients with and without previous GBP was investigated both in the whole cohort and in a 1:1 nested case-control subset. In the nested case-control group, patients with TT with previous GBP were randomly matched to patients without previous GBP, on the factors age, gender, lymph node dissection or not, and indication for surgery.

Means and standard deviations (SD) were calculated for continuous variables except for age. Age is reported as median and range. Numbers and column percentages were calculated for categorical variables.

In the whole cohort, risk for treatment with calcium and vitamin $\mathrm{D}$ at different times of follow-up, in patients with and without GBP, was investigated with uni- and multivariate logistic regression, adjusting for possible confounding variables: age, gender, indication for surgery, and lymph node dissection. In the nested case-control subset, ANOVA, chisquare, or Fisher's exact tests were used to determine the association of primary endpoints with previous GBP. All analyses were performed with STATA 13 (StataCorp LP, College Station, TX, USA). A $p$ value of less than 0.05 was considered statistically significant.

This study was performed and reported according to the Strengthening the Reporting of Observational Studies in Epidemiology statement [21]. 


\section{Results}

\section{Baseline patient and procedure characteristics in the overall cohort}

There were 7600 patients who underwent TT. Of these, we excluded 217 patients due to prior or concurrent parathyroidectomy. Another seven patients lacked information on treatment for postoperative hypocalcemia. Patients that were operated before 1 May 2007 (start date of the SOReg) were also excluded $(N=1261)$. This left 6115 patients for analysis. By cross-linking with SOReg, 25 patients with GBP before TT were identified, corresponding to a rate of 25/6115 (0.4\%).

The median age in the cohort was 46 (33-59), male to female ratio was $1: 4$, and the indication for surgery was thyrotoxicosis in half of the patients. Mean (SD) postoperative total calcium was $2.13( \pm 0.20$; Table 1$)$ at day one. Total calcium at 6-week and 6-month follow-up were $2.30( \pm 0.17)$ and $2.25( \pm 0.17)$, respectively. At 6-week follow-up, 841 (13.8\%) had oral calcium and 554 patients $(9.1 \%)$ vitamin D substitution for hypocalcemia. These numbers were 290 $(4.7 \%)$ and 214 (3.5\%) at 6-month follow-up. Baseline characteristics are summarized in Table 1.

The number of patients without follow-up information for oral calcium treatment at 6 weeks and 6 months were 481 (7.9\%) and $641(10.5 \%)$, respectively.

\section{Patient and procedure characteristics in patients with and without previous GBP}

In the whole cohort, there were no statistically significant differences between patients with and without previous GBP regarding age (median, (IQR)) 48 (41-52) vs 46 (33-59); $p=0.977)$, male to female ratio (4/21 vs $1230 / 4860$; $p=0.602$ ) and postoperative total calcium (mean, (SD) 2.13 $( \pm 0.16) \mathrm{mmol} / \mathrm{l}$ vs $2.12( \pm 0.20) \mathrm{mmol} / \mathrm{l} ; p=0.997)$. However, there was a significant difference for the indication for thyroidectomy $(p=0.015)$. The most common indication for TT overall was thyreotoxicosis; in patients with previous GBP, it was compression symptoms.

Total serum calcium and rates of calcium and/or vitamin D substitution at 6-week and 6-month follow-up after thyroidectomy did not differ significantly between patients with and without previous GBP in the whole cohort (Table 2).

\section{Logistic regression analysis of hypocalcemia, vitamin D and calcium treatment at discharge and follow-up in the whole cohort}

In the multivariate logistic regression analysis including age, gender, lymph node dissection, and indication for surgery, previous gastric bypass was not associated with in hospital treatment with i.v. or oral calcium $(2.07(0.48-9.07) ; 0.89$
Table 1 Characteristics of patients operated with total thyroidectomy registered in the SQRTPA from 1 May 2007-2015 $(N=6115)$

\begin{tabular}{|c|c|}
\hline & $N=6115(100 \%)$ \\
\hline Age median (IQR) & $46(33-59)$ \\
\hline \multicolumn{2}{|l|}{ Sex } \\
\hline Male & $1234(20.2)$ \\
\hline Female & $4881(79.8)$ \\
\hline \multicolumn{2}{|l|}{ Indication for thyroidectomy } \\
\hline Recurrent cyst & $12(0.2)$ \\
\hline Completion operation & $17(0.3)$ \\
\hline Excluding malignancy & $457(7.5)$ \\
\hline Malignancy & $956(15.6)$ \\
\hline Compression & $1586(25.9)$ \\
\hline Thyrotoxicosis & $3063(50.1)$ \\
\hline Other & $24(0.4)$ \\
\hline \multicolumn{2}{|l|}{ Lymphnode dissection } \\
\hline Yes & $1068(17.5)$ \\
\hline No & $5047(82.5)$ \\
\hline Gland weight (grams) & $74.2( \pm 94.0)$ \\
\hline \multicolumn{2}{|l|}{ Oral perioperative calcium treatment } \\
\hline Yes & 2055 (33.6) \\
\hline No & $4060(66.4)$ \\
\hline \multicolumn{2}{|l|}{ Intravenous calcium treatment } \\
\hline Yes & $250(4.1)$ \\
\hline No & $5865(95.9)$ \\
\hline \multicolumn{2}{|l|}{ Peroral calcium treatment } \\
\hline At discharge (yes/no) & $1776(29.0) / 4339(71.0)$ \\
\hline At 6 weeks follow-up (yes/no) & $841(13.8) / 4793(78.4)$ \\
\hline At 6 months follow-up (yes/no) & $290(4.7) / 5184(84.8)$ \\
\hline \multicolumn{2}{|l|}{ Total serum calcium } \\
\hline Postoperative day 1 & $2.13( \pm 0.20)$ \\
\hline At 6 weeks follow-up & $2.30( \pm 0.17)$ \\
\hline At 6 months follow-up & $2.25( \pm 0.17)$ \\
\hline \multicolumn{2}{|l|}{ Peroral vitamin D treatment } \\
\hline At discharge (yes/no) & $909(14.9) / 5206(85.1)$ \\
\hline At 6 weeks follow-up (yes/no) & $554(9.1) / 5087(83.2)$ \\
\hline At 6 months follow-up (yes/no) & $214(3.5) / 5333(87.2)$ \\
\hline
\end{tabular}

$I Q R$ interquartile range, $G B P$ gastric bypass

(0.37-2.11)), oral calcium, and/or vitamin D at discharge $(0.75(0.29-1.91) ; 1.37(0.50-3.76))$, at 6 weeks $(1.11$ $(0.37-3.31) ; 1.25(0.36-4.27))$, or 6 months postoperatively (1.45 (0.33-6.36); 2.01 (0.46-8.77); Tables 3 and 4).

\section{Endpoints in patients with and without previous GBP in the nested case-control group}

For the matched nested case-control analysis, the 25 patients with GBP before TT were successfully matched to an equal 
Table 2 Endpoint characteristics of group without and with previous GBP in the overall cohort $(N=6115)$

\begin{tabular}{|c|c|c|c|}
\hline & No previous GBP $N=6090(100 \%)$ & Previous GBP $N=25(100 \%)$ & $p$ value \\
\hline Age median (IQR) & $46(33-59)$ & $48(41-52)$ & 0.977 \\
\hline \multicolumn{4}{|l|}{ Sex } \\
\hline Male & $1230(20.2)$ & $4(16.0)$ & \multirow[t]{2}{*}{0.602} \\
\hline Female & $4860(79.8)$ & $21(84.0)$ & \\
\hline \multicolumn{4}{|l|}{ Indication for thyroidectomy } \\
\hline Recurrent cyst & $12(0.2)$ & $0(0.0)$ & \multirow[t]{7}{*}{0.015} \\
\hline Completion operation & $17(0.3)$ & $0(0.0)$ & \\
\hline Excluding malignancy & $454(7.5)$ & $3(12.0)$ & \\
\hline Malignancy & $949(15.6)$ & $7(28.0)$ & \\
\hline Compression & $1575(25.9)$ & $11(44.0)$ & \\
\hline Thyreotoxicosis & $3059(50.2)$ & $4(16.0)$ & \\
\hline Other & $24(0.4)$ & $0(0.0)$ & \\
\hline \multicolumn{4}{|l|}{ Lymphnode dissection } \\
\hline Yes & $1061(17.4)$ & $7(28.0)$ & \multirow[t]{2}{*}{0.164} \\
\hline No & $5029(82.6)$ & $18(72.0)$ & \\
\hline Gland weight (grams) & $74.1( \pm 94.0)$ & $80.7( \pm 72.2)$ & 0.748 \\
\hline \multicolumn{4}{|l|}{ Oral perioperative calcium treatment } \\
\hline Yes & $2047(33.6)$ & $8(32.0)$ & \multirow[t]{2}{*}{0.865} \\
\hline No & $4043(66.4)$ & $17(68.0)$ & \\
\hline \multicolumn{4}{|l|}{ Intravenous calcium treatment } \\
\hline Yes & $248(4.1)$ & $2(8.0)$ & \multirow[t]{2}{*}{0.322} \\
\hline No & $5842(95.9)$ & $23(92.0)$ & \\
\hline \multicolumn{4}{|l|}{ Peroral calcium treatment } \\
\hline At discharge (yes/no) & $1770(29.1) / 4320(70.9)$ & $6(24.0) / 19(76.0)$ & 0.578 \\
\hline At 6 weeks follow-up (yes/no) & $837(13.7) / 4773(78.4)$ & $4(16.0) / 20(80.0)$ & 0.651 \\
\hline At 6 months follow-up (yes/no) & $288(4.7) / 5163(84.8)$ & $2(8.0) / 21(84.0)$ & 0.373 \\
\hline \multicolumn{4}{|l|}{ Total serum calcium } \\
\hline Postoperative day 1 & $2.12( \pm 0.20)$ & $2.13( \pm 0.16)$ & 0.997 \\
\hline At 6 weeks follow-up & $2.30( \pm 0.17)$ & $2.27( \pm 0.13)$ & 0.305 \\
\hline At 6 months follow-up & $2.25( \pm 0.17)$ & $2.26( \pm 0.10)$ & 0.901 \\
\hline \multicolumn{4}{|l|}{ Peroral vitamin D treatment } \\
\hline At discharge (yes/no) & $904(14.8) / 5186(85.2)$ & $5(20.0) / 20(80.0)$ & 0.470 \\
\hline At 6 weeks follow-up (yes/no) & $551(9.0) / 5066(83.2)$ & $3(12.0) / 21(84.0)$ & 0.616 \\
\hline At 6 months follow-up (yes/no) & $212(3.5) / 5311(87.2)$ & $2(8.0) / 22(88.0)$ & 0.278 \\
\hline
\end{tabular}

$I Q R$ interquartile range, GBP gastric bypass

number of controls. Mean postoperative total calcium on day one was $2.13( \pm 0.16) \mathrm{mmol} / \mathrm{l}$ in patients with previous GBP, vs $2.16( \pm 0.15 ; p=0.450) \mathrm{mmol} / \mathrm{l}$ in patients without. Mean total serum calcium and rates of calcium and/or vitamin $\mathrm{D}$ substitution at 6-week and 6-month follow-up after thyroidectomy did not differ between patients with and without previous GBP (Table 5).

\section{Discussion}

Case reports and our own experience have suggested that patients with previous GBP suffer an increased risk of severe hypocalcemia after TT [1-3], compared to patients without GBP. GBP, the most common bariatric procedure, is associated with nutritional deficiencies [22], such as low levels of 25OHD and diminished uptake of dietary calcium. Low levels of 25OHD have been shown to be a risk factor for postoperative hypocalcemia after TT and central neck dissection [8]. An increased risk of hypocalcemia after TT with previous GBP compared to TT without previous GBP is therefore plausible.

However, the hypothesis that patients with previous GBP have an increased risk of hypocalcemia after TT could not be confirmed in this large, population-based, nationwide cohort study. GBP was not a risk factor for hypocalcemia in uni- or 


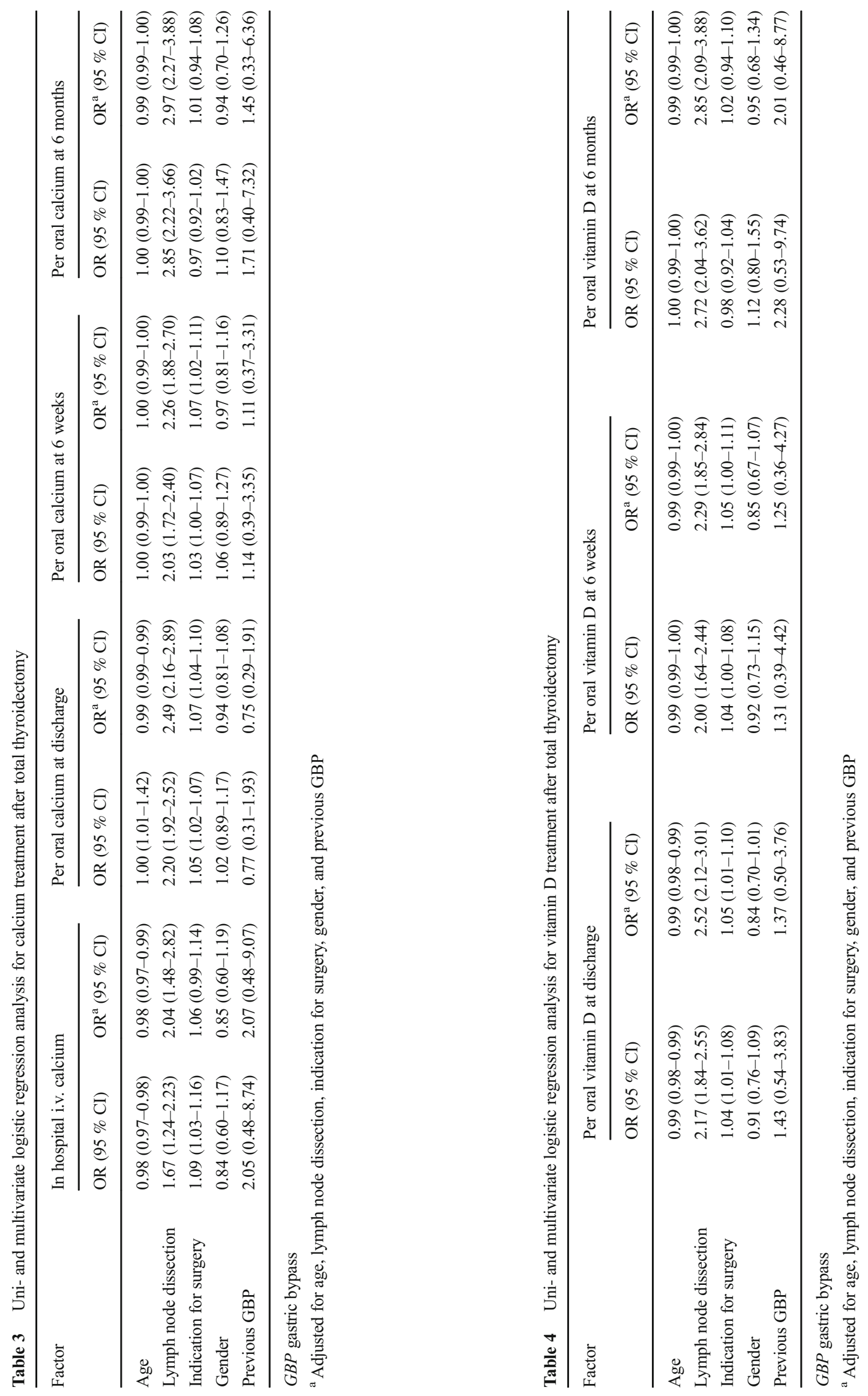


Table 5 Results of 1:1 nested case-control analysis

\begin{tabular}{|c|c|c|c|}
\hline & $\begin{array}{l}\text { No previous GBP } N=25 \\
(100 \%)\end{array}$ & $\begin{array}{l}\text { Previous GBP } N=25 \\
(100 \%)\end{array}$ & $p$ value \\
\hline Age median (IQR) & $48(41-52)$ & $48(41-52)$ & 1.000 \\
\hline \multicolumn{4}{|l|}{ Sex } \\
\hline Male & $4(16.0)$ & $4(16.0)$ & \multirow[t]{2}{*}{1.000} \\
\hline Female & $21(84.0)$ & $21(84.0)$ & \\
\hline \multicolumn{4}{|l|}{ Indication for thyroidectomy } \\
\hline Recurrent cyst & $0(0.0)$ & $0(0.0)$ & \multirow[t]{7}{*}{1.000} \\
\hline Completion operation & $0(0.0)$ & $0(0.0)$ & \\
\hline Excluding malignancy & $3(12.0)$ & $3(12.0)$ & \\
\hline Malignancy & $7(28.0)$ & $7(28.0)$ & \\
\hline Compression & $11(44.0)$ & $11(44.0)$ & \\
\hline Thyreotoxicosis & $4(16.0)$ & $4(16.0)$ & \\
\hline Other & $0(0.0)$ & $0(0.0)$ & \\
\hline \multicolumn{4}{|l|}{ Lymphnode dissection } \\
\hline Yes & $7(28.0)$ & $7(28.0)$ & \multirow[t]{2}{*}{1.000} \\
\hline No & $18(72.0)$ & $18(72.0)$ & \\
\hline Gland weight (grams) & $74.0( \pm 61.7)$ & $80.7( \pm 72.2)$ & 0.737 \\
\hline \multicolumn{4}{|c|}{ Oral perioperative calcium treatment } \\
\hline Yes & $10(40.0)$ & $8(32.0)$ & \multirow[t]{2}{*}{0.556} \\
\hline No & $15(60.0)$ & $17(68.0)$ & \\
\hline \multicolumn{4}{|l|}{ Intravenous calcium treatment } \\
\hline Yes & $0(0.0)$ & $2(8.0)$ & \multirow[t]{2}{*}{0.149} \\
\hline No & $25(100.0)$ & $23(92.0)$ & \\
\hline \multicolumn{4}{|l|}{ Peroral calcium treatment } \\
\hline At discharge (yes/no) & $8(32.0) / 17(68.0)$ & $6(24.0) / 19(76.0)$ & 0.935 \\
\hline $\begin{array}{l}\text { At } 6 \text { weeks follow-up (yes/ } \\
\text { no) }\end{array}$ & $6(24.0) / 17(68.0)$ & $4(16.0) / 20(80.0)$ & 0.727 \\
\hline $\begin{array}{l}\text { At } 6 \text { months follow-up (yes/ } \\
\text { no) }\end{array}$ & $2(8.0) / 20(80.0)$ & $2(8.0) / 21(84.0)$ & 0.599 \\
\hline \multicolumn{4}{|l|}{ Total serum calcium } \\
\hline Postoperative day 1 & $2.16( \pm 0.15)$ & $2.13( \pm 0.16)$ & 0.450 \\
\hline At 6 weeks follow-up & $2.31( \pm 0.14)$ & $2.27( \pm 0.13)$ & 0.276 \\
\hline At 6 months follow-up & $2.14( \pm 0.18)$ & $2.26( \pm 0.10)$ & 0.160 \\
\hline \multicolumn{4}{|l|}{ Peroral vitamin $\mathrm{D}$ treatment } \\
\hline At discharge (yes/no) & $6(24.0) / 19(76.0)$ & $5(20.0) / 20(80.0)$ & 0.733 \\
\hline $\begin{array}{l}\text { At } 6 \text { weeks follow-up (yes/ } \\
\text { no) }\end{array}$ & $4(16.0) / 19(76.0)$ & $3(12.0) / 21(84.0)$ & 0.329 \\
\hline $\begin{array}{l}\text { At } 6 \text { months follow-up (yes/ } \\
\text { no) }\end{array}$ & $1(4.0) / 21(84.0)$ & $2(8.0) / 22(88.0)$ & 0.188 \\
\hline
\end{tabular}

$I Q R$ interquartile range, $G B P$ gastric bypass multivariate logistic regression, and the rate of hypocalcemia was similar between previous GBP and no previous GBP in a nested case-control subset. Further, the frequency of previous GBP in patients undergoing TT was low, only $0.4 \%$.

The number of patients who underwent both first gastric bypass surgery and then total thyroidectomy was low in this study. However, taking into account that two nationwide registers, based on the whole Swedish population of about nine million people, were used; we consider this finding a strength rather than a weakness.
Another potential explanation for the lack of an association could be missing observations. The Swedish Obesity Register, SOReg, started in May 2007, and no bariatric procedures performed before this date could be included in our study. Hence, it is possible that our study underestimates the rate of previous GBP in patients with TT. However, this seems to be rather unlikely since only 6-18 operations/100,000 were performed 2002-2006 and 24-89 operations/100,000 were performed 2007-2014 (Fig. 1S). Furthermore, the SOReg has a coverage of almost $100 \%$ and it is unlikely that GBPs performed after 
May 2007 were missed in the patients in the present study [20].

The possibility of inaccurate data must also be taken into account. If treatment for hypocalcemia is inaccurately reported to the registry, the true frequency of this complication could be underestimated. However, the SQRTPA is audited regularly and data quality has been shown to be good. Further, data on treatment for hypocalcemia would likely be missing or inaccurate at random, and it is unlikely that this would systematically bias the results.

With only 25 patients with previous GBP, the study might be underpowered to detect a true difference in the rate of hypocalcemia after TT with and without previous GBP. While we did not observe any difference, it must be emphasized that our study does not prove the absence of such a difference.

The rate of calcium and/or vitamin D treatment in the whole cohort and in the nested control group was rather high, $4.7 \%$. This high rate could make it difficult to detect a true increase in the risk of hypocalcemia after TT in patients with previous GBP. An explanation for the high rate of hypocalcemia in the whole cohort could be the inclusion of low-volume hospitals in the registry. Another reason for the high rate of hypocalcemia overall in this study could be the high proportion of TT for thyrotoxicosis, more than $50 \%$, since previous studies indicate that TT for thyrotoxicosis carries a higher risk of long-term hypocalcemia. However, when adjusting for thyrotoxicosis in the multivariate logistic regression analysis, there was no significant increased risk of hypocalcemia after TT with previous GBP.

Another explanation for the disagreement with the present study and previous case reports [1-3] could be that patients with previous GBP in the present study had sufficient levels of 25OHD, and that patients in case reports had insufficient levels of 25OHD. Unfortunately, we did not have information about levels of 25OHD.

Furthermore, the time between GBP and TT could be important. Calcium and vitamin $\mathrm{D}$ depletion could aggravate over time after GBP. Perhaps GBP does not increase the risk of hypocalcemia after TT during the first years postoperatively, and this might be another explanation to the lack of association between GBP and hypocalcemia after TT in our study, since the time interval was in no patient longer than 7 years.

Similar to previous studies [23-25], age, gender, indication for surgery, and lymph node dissection were risk factors for postoperative hypocalcemia in our study.

The major strengths of this study include the large number of patients with TT; the truly population-based design with registers having wide national coverage; the high external validity including 35 Swedish units, ranging from small rural county hospitals to large university hospitals; and the high data quality in terms of coverage and accuracy, with nearly $100 \%$ coverage for obesity surgery. Further, there were low numbers of patients with missing information for oral calcium treatment at 6 weeks and 6 months [18-20].

\section{Conclusion}

In conclusion, the results of this large observational study did not provide evidence for an increased risk for hypocalcemia after TT compared to patients without previous GBP. This study does neither support giving any extra supplementation to nor taking any extra blood tests in patients with previous GBP before TT, since their risk of hypocalcemia does not seem to markedly differ from the overall TT cohort.

Acknowledgments The authors thank the participating centers of the Scandinavian Obesity Surgery Registry and Scandinavian Quality Registry for Thyroid, Parathyroid and Adrenal Surgery, who were indispensable in collecting and reporting the data required for the present study.

Authors' contributions Study conception and design: MA, AB.

Acquisition of data: JO, AM, HH, KL, AB, MA.

Analysis and interpretation of data: RD, MA, AB.

Drafting of manuscript: RD, MA.

Critical revision of manuscript: JO, AM, AB.

Compliance with ethical standards This study was approved by the research ethics committee at Lund University, DNR 2015/543 and 2016/83

Conflict of interest statement None declared. The present study was submitted and accepted for oral presentation at the 7th Biennial Congress of the European Society of Endocrine Surgeons (ESES). Apart from this, the results presented in this paper have not been published previously in whole or part.

Funding This study received donations from Skane University Hospital, The Anna Lisa and Sven-Erik Lundgren Foundation for Medical Research, Southern Health Care Region Grants, and Novartis Health Alliance. The funders had no role in study design, data collection and analysis, decision to publish, or preparation of the manuscript.

Open Access This article is distributed under the terms of the Creative Commons Attribution 4.0 International License (http:// creativecommons.org/licenses/by/4.0/), which permits unrestricted use, distribution, and reproduction in any medium, provided you give appropriate credit to the original author(s) and the source, provide a link to the Creative Commons license, and indicate if changes were made.

\section{References}

1. Alfonso B, Jacobson AS, Alon EE, Via MA (2015) Previous gastric bypass surgery complicating total thyroidectomy. Ear Nose Throat J 94:E12-E16

2. Salinger EM, Moore JT (2010) Profound hypocalcemia after neartotal thyroidectomy in a Roux-en-Y gastric bypass patient. Am Surg 76:E7-E8 
3. Pietras SM, Holick MF (2009) Refractory hypocalcemia following near-total thyroidectomy in a patient with a prior Roux-en-Y gastric bypass. Obes Surg 19:524-526. doi:10.1007/s11695008-9614-8

4. Yatsuya H, Li Y, Hilawe EH et al (2014) Global trend in overweight and obesity and its association with cardiovascular disease incidence. Circ J 78:2807-2818

5. Efremidou EI, Papageorgiou MS, Liratzopoulos N, Manolas KJ (2009) The efficacy and safety of total thyroidectomy in the management of benign thyroid disease: a review of 932 cases. Can J Surg 52:39-44

6. Bhattacharyya N, Fried MP (2002) Assessment of the morbidity and complications of total thyroidectomy. Arch Otolaryngol Head Neck Surg 128:389-392

7. Yamashita H, Murakami T, Noguchi S et al (1999) Postoperative tetany in Graves disease: important role of vitamin D metabolites. Ann Surg 229:237-245

8. Kim WW, Chung S-H, Ban EJ et al (2015) Is preoperative vitamin D deficiency a risk factor for postoperative symptomatic hypocalcemia in thyroid cancer patients undergoing total thyroidectomy plus central compartment neck dissection? Thyroid 25:911-918. doi: $10.1089 /$ thy. 2014.0522

9. le Roux CW, Bueter M (2014) The physiology of altered eating behaviour after Roux-en-Y gastric bypass. Exp Physiol 99:11281132. doi:10.1113/expphysiol.2014.078378

10. Shah M, Simha V, Garg A (2006) Review: long-term impact of bariatric surgery on body weight, comorbidities, and nutritional status. J Clin Endocrinol Metab 91:4223-4231. doi:10.1210 /jc.2006-0557

11. Elias E, Casselbrant A, Werling $M$ et al (2014) Bone mineral density and expression of vitamin D receptor-dependent calcium uptake mechanisms in the proximal small intestine after bariatric surgery. Br J Surg 101:1566-1575. doi:10.1002 /bjs.9626

12. Karefylakis C, Naslund I, Edholm D et al (2014) Vitamin D status 10 years after primary gastric bypass: gravely high prevalence of hypovitaminosis D and raised PTH levels. Obes Surg 24:343-348. doi:10.1007/s11695-013-1104-y
13. Liu C, Wu D, Zhang J-F et al (2016) Changes in bone metabolism in morbidly obese patients after bariatric surgery: a meta-analysis. Obes Surg 26:91-97. doi:10.1007/s11695-015-1724-5

14. Lu C-W, Chang Y-K, Chang H-H et al (2015) Fracture risk after bariatric surgery: a 12-year nationwide cohort study. Medicine (Baltimore) 94:e2087. doi:10.1097/MD.0000000000002087

15. Levinson R, Silverman JB, Catella JG et al (2013) Pharmacotherapy prevention and management of nutritional deficiencies post Roux-en-Y gastric bypass. Obes Surg 23:992-1000. doi:10.1007/s11695-013-0922-2

16. Hessman C, Fields J, Schuman E (2011) Outpatient thyroidectomy: is it a safe and reasonable option? Am J Surg 201:565-568. doi:10.1016/j.amjsurg.2011.01.023

17. Snyder SK, Hamid KS, Roberson CR et al (2010) Outpatient thyroidectomy is safe and reasonable: experience with more than 1,000 planned outpatient procedures. J Am Coll Surg 210:575-582 . doi:10.1016/j.jamcollsurg.2009.12.037582-584

18. Swedish National Board of Health and Welfare: http://www. socialstyrelsen.se/english.

19. Scandinavian Quality register for Thyroid Parathyroid and Adrenal Surgery:http://www.thyroid-parathyroidsurgerty.com/.

20. Hedenbro JL, Naslund E, Boman L et al (2015) Formation of the Scandinavian obesity surgery registry, SOReg. Obes Surg 25:18931900. doi:10.1007/s11695-015-1619-5

21. von Elm E, Altman DG, Egger M et al (2014) The strengthening the reporting of observational studies in epidemiology (STROBE) statement: guidelines for reporting observational studies. Int $\mathrm{J}$ Surg 12:1495-1499. doi:10.1016/j.ijsu.2014.07.013

22. Bal BS, Finelli FC, Shope TR, Koch TR (2012) Nutritional deficiencies after bariatric surgery. Nat Rev Endocrinol 8:544-556. doi:10.1038/nrendo.2012.48

23. Abboud B, Sargi Z, Akkam M, Sleilaty F (2002) Risk factors for postthyroidectomy hypocalcemia. J Am Coll Surg 195:456-461

24. Wingert DJ, Friesen SR, Iliopoulos JI et al (1986) Postthyroidectomy hypocalcemia. Incidence and risk factors. Am J Surg 152:606-610

25. McHenry CR, Speroff T, Wentworth D, Murphy T (1994) Risk factors for postthyroidectomy hypocalcemia. Surgery 116:641-648 